\title{
Matching The International Federation Of Accountant's International Education Guideline 11 To AIS Textbooks: An Examination Of The Current State Of Topic Coverage \\ Greg Krippel, (E-mail: krippel@ coastal.edu), Coastal Carolina University Janette Moody, (E-mail: moodyj@ citadel.edu), The Citadel
}

\begin{abstract}
The challenges for professors teaching the AIS course are numerous as the breadth of information technology [IT] topics to be covered continues to expand, leaving the question of which topics are of most importance. For the majority of AIS professors, the AIS text is the primary guide on these decisions. This paper reviews the contents of eleven well-regarded AIS texts through the framework of the IT knowledge components suggested by the International Federation of Accountants [IFAC]. The findings suggest that current AIS texts are addressing many of the IFAC broad areas of knowledge, although with varying emphasis on selected topics. The analysis presented here will be useful in determining not only which text may best fit the AIS professor's needs, but also in identifying when supplemental materials may be required to provide additional topic coverage.
\end{abstract}

\section{INTRODUCTION}

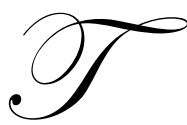

he inclusion in the accounting curriculum of a course devoted to the use of computers in organizations had a tentative start in the late 1960s (Wu, 1983) as practitioners and academics recognized the need to expand the accountant's knowledge of computer-based information systems (Davis, 1976, 1979). As would be expected during the developmental stages of what is now primarily known as the Accounting Information Systems (AIS) course, there was little agreement regarding the topics to be included (Cerullo, 1981), with the situation further "aggravated by a variety of AIS textbooks covering different topics at different lengths" (Wu, 1983, p. 133). Over two decades later, many AIS professors would agree that determining the topics to be included in the AIS course remains challenging, and that while the number of AIS textbooks has increased, so has the complexity of choosing one. Fortunately, guidance regarding topics of importance for preparing professional accountants to work in the information technology environment in the various roles of user, manager, designer, and/or evaluator has been provided by the International Federation of Accountants (IFAC). Therefore, the aim of this paper is to address the challenges of teaching the AIS course through a review of how well current AIS textbooks provide coverage of topics recommended by IFAC. In doing so, we contribute to and update a well-established research stream of continuing examination and support of the AIS course. We begin by reviewing previous work done in this area. We next describe the methodology used in our research project, present our findings and provide suggestions for future research. 


\section{BACKGROUND}

\section{Prior Research On AIS Course Topics}

Since the introduction in the late 1960's of a course devoted to the use of computers into the accounting curriculum, several attempts have been to track AIS course content and instructional resources, both in the U.S. and abroad. In the absence of an agreed upon set of information technology (IT) topics, early researchers looked to practitioners, professional bodies, and AIS educators for guidance on topics to be covered.

For example, Heagy and McMickle, (1988) looked to practitioners for input of AIS topics of importance. They found that although agreeing on about one-third of the topics, practitioners wanted more emphasis on spreadsheets and internal controls than did academics. Davis and Leitch (1988) compared recent graduates' rankings of importance for selected AIS topics versus AIS educators' rankings and found that recent graduates ranked microcomputer software significantly more important than did the educators. Groomer and Murthy (1996) surveyed accounting department chairpersons and AIS instructors about topics covered and instructional materials used, among other items. They found that AIS instructors were dissatisfied with the available AIS texts and, at that time, relied primarily on instructor-prepared notes, leading one to conclude that topical coverage would be as diverse as the instructors based on their backgrounds and areas of interest. Groomer and Murthy (1996) attributed this diversity of content coverage to a lack of external authoritative guidance on topics to be covered as well as the diversity of backgrounds and skills of the instructors. Macur (1998) reviewed 56 AIS syllabi and found that eight of the courses did not use a textbook while the remaining 48 courses used one of nine AIS texts popular at that time. He found over half of the respondents covered up to 78\% of AAA suggested topics and over $85 \%$ used at least one software project suggested by IFAC and AICPA. Macur (1998) went on to note that perhaps seeking consensus in AIS topics actually undermines the basic premise of creativity inherent in the development and use of information systems, and is not necessarily a laudable goal for AIS instructors. Theuri and Gunn's (1998) research concluded that AIS course content was often influenced first by employers, and secondly by CPA exam requirements. ${ }^{1}$ They found that employers (accounting firms, government, and corporations) of accounting graduates considered database management concepts to be of less importance than did AIS faculty, and were not interested in what were then considered emerging technologies such as distributed systems and decision support systems.

Hermanson, Callhan-Hill, and Ivancevich (1999) surveyed 69 accounting faculty and found that although they believed it important to integrate IT into the curriculum, in reality such integration was weak. They found only minor-to-moderate coverage of IFAC suggested general IT topics. They reported the most covered individual topics in the AIS course were: general systems concepts, risks and exposures in computer-based information, transaction processing in typical applications, and data organization and access methods. Richtermeyer and Kovar's (2001) survey of 50 AIS educators found that they continue to cover many of the emerging technology topics identified by the AICPA, using a blending of approaches, including the transaction cycle approach (based on the accounting cycle) and the business process approach (the capture of all organizational information, not just accounting information). Bain et al. (2002) examined AIS texts, online course syllabi, and input from professionals and faculty to find a consensus that the main topics of importance were "introduction to systems", "transaction processing", and "internal controls". Bain et al. (2002) argued that one of the key difficulties in teaching AIS is the lack of a standardized curriculum for the course.

Similar results were found overseas. Hogan (2003), based on a survey of 15 Australian universities, concluded that the topical coverage in AIS courses varied widely. Chayeb and Best (2005) surveyed 18 Australian universities and found that over $44 \%$ of the AIS instructors were unaware that IFAC had published guidelines on topical coverage, although they did find "reasonable consistency" in AIS course content in the surveyed universities. They also found that a lack of suitable textbooks constituted a major concern, mirroring the decades earlier Groomer and Murthy (1996) findings. To supplement the materials in textbooks, Schiff and Lavine (2001) provided an

\footnotetext{
${ }^{1}$ Macur (1998) noted that the CPA exam is a poor guide for the AIS curriculum because historically IT topics average only 4-6 points out of 100 on the auditing section of the exam.
} 
overview of 280 MIS journal articles as an instructional resource for AIS educators. Palmer et al. (2004) summarized the diversity of skills including IT skills, mandated by professional organizations, including the American Accounting Association (AAA), the Institute of Management Accountants (IMA), Financial Executives Institute (FEI), the Institute of Internal Auditors (IIA), and the International Federation of Accountants (IFAC), concluding that while there are some commonalities, it is likely that educators will feel "overwhelmed and confused" when assessing and designing AIS curriculum. Wessels (2005) also looked at the requirements of various professional bodies to determine a consensus of technology skills requirements. He provided an extensive review of the competency requirements of the Institute of Chartered Accountants of Australia (ICAA), the Canadian Institute of Chartered Accountants (CICA), the Institute of Chartered Accountants in England and Wales (ICA EW) , the American Institute of Certified Public Accountants (AICPA), the South African Institute of Charted Accountants (SAICA), the Chartered Institute of Management Accountants (CIMA), the Institute of Management Accountants (IMA), and the International Federation of Accountants (IFAC). He concluded that despite having different areas of focus, each recognized the importance of accountants being technologically skilled. It can also be noted that even with extensive guidelines from international and national professional bodies, sometimes the direction of AIS curriculum content may come from entities closer to home. Fordham (2005) presents a case study of determining AIS curriculum topics from the collective input of the university's advisory board members, current and potential recruiters, as well as alumni and graduates of the AIS program.

\section{Guidance For AIS Topics: History And Purpose Of IFAC And IEPS 2}

As can be seen from the above discussion, researchers have historically examined AIS syllabi to determine the content of AIS courses and their relationships to various inputs from professional bodies, practitioners, and other AIS educators, without finding consensus. However, as noted earlier, one professional body that provides current and detailed guidance regarding IT topics for accountants is IFAC. IFAC's International Accounting Education Standards Board, formerly known as the Education Committee, provided extensive guidance regarding important IT topics in 1995 in its International Education Guideline 11 (IEG 11), which was adopted without modification by the AICPA in 1997, revised in 1998 and 2002, and is now known as Education Practice Statement 2 (IEPS 2). These revisions attest to IFAC's acknowledgement and monitoring of the rapid change in IT and its business applications both for accountants and their clients.

Founded in 1977, IFAC is a worldwide organization representing accountants in 120 countries employed in public practice, industry, government, and academe. Its goals are to be: 1) a facilitator of communication and collaboration among its members, 2) a promoter of high international standards, and 3) a spokesperson for the profession on issues of public interest (www.ifac.org). To achieve these goals it has formed various boards and committees, one of which is the International Accounting Education Standards Board (IAESB) which develops the International Education Practice Statements (IEPS). IEPS 2, Information Technology for Professional Accountants, was developed to assist in preparing professional accountants to work in the information technology environment in the various roles of user, manager, designer, and/or evaluator. In this context, IT is defined as "hardware, and software products, information system operations and management processes, and the human resources and skills required to apply those products and processes to the task of information production and information systems development, operation, management and control" (IEPS 2, pg. 7).

While recognizing the challenges associated with defining a common body of knowledge and competencies for its members, IFAC nevertheless stresses the importance of including coverage of major "IT knowledge and competency areas in prequalification education programs, prequalification work experience and post-qualification professional education" (IEPS 2, pg. 13). It is recommended that during the prequalification phase, the emphasis should be on broad IT competencies while post-qualification will expand to an emphasis on topics related to the specialized needs of the work domain. In addition to providing a set of IT capabilities, IEPS 2 also includes a set of IT tasks the accountant should be able to perform. By doing so, IEPS 2 not only addresses input-based factors (knowledge about various IT topics) but also the output-based IT tasks and sub-tasks that the accountant must perform. (For a comprehensive discussion of IT competencies versus IT knowledge, see Carnaghan, 2004). 
This paper provides an updated look at current AIS topic coverage by comparing eleven top AIS textbooks to the IFAC guidelines in order to determine the texts' coverage of the suggested IT topics. In doing so, the paper provides 1) guidance to AIS instructors interested in selecting the appropriate AIS text(s) in light of their university's course requirements and offerings, 2) support to accounting curriculum committees charged with determining the number of IT courses to offer accounting majors, and 3) feedback to current and future AIS text authors regarding the breadth and depth of IT topics deemed by IFAC as important for an accountant. It is not this paper's intent to critique the quality or depth of IT topic coverage in any specific text but rather to provide a convenient and succinct review of topical coverage in order to note specializations, identify areas of opportunity for supplemental class exercises, and other guidance for AIS instructors.

In summary, past research has given us some insights on the critical question: What should be included in the content of an AIS course? In an effort to gather evidence regarding the answer or answers to this question previous researchers have surveyed the three major classes of stakeholders; AIS professors, practitioners and professional bodies. The research evidence suggests that AIS professors are not in agreement as to the content of the AIS course, which is not surprising in light of their varying levels of interests and skills plus the breadth of AIS topics possible. The next logical place to look for guidance was to survey practitioners. Evidence suggests that there are many areas of disagreement between the ranking of importance of AIS topics between AIS educators and practitioners. To help sort this out, the third step was for professional bodies to establish IT topics guidelines by forming panels of experts that included both educators and practitioners. As we have seen, because these professional bodies represented very different segments of the accounting profession and different interest groups, it is not surprising that often the guidelines from these professional bodies still provided few AIS topics commonalities.

Fortunately, the guidelines from IFAC were designed to avoid these conflicts as they address the "essential body of general IT knowledge related to business systems" (p. 21) needed by accountants, "irrespective of their primary work domain or role" (ibid). An overview of IFAC's essential body of knowledge is presented in Table 1. In addition to this recommended general body of IT knowledge, IFAC provides guidance on topics of importance as accountants specialize in their roles of: Users of IT, Managers of IT, Designers of IT, and Evaluators of IT. It should be noted that IFAC does not consider these roles to be mutually exclusive nor to occur sequentially in practice. Furthermore, the IFAC panel recognized that the extensive topical coverage recommended in IEPS 2 could not be obtained in a single course and recommended a minimum of two courses consisting of 40 hours in-class with an additional 80 hours of outside work in preparation, homework, etc.

Regardless of how many courses are offered, a major tool for delivering the course is an AIS textbook, which raises the question of how well current AIS textbooks comply with IFAC's suggested topics. Therefore our research addresses the question: to what extent do current AIS textbooks cover the AIS broad topic areas and specific sub-topics recommended by the IFAC educational standards? In the following Methodology section we describe how we gathered evidence to answer this question.

\section{METHODOLGY}

Table 1 provides the top-level framework used to analyze the AIS texts, consisting of six broad knowledge areas (BKA) from the five BKA of IEPS 2's General Information Technology Knowledge Requirements (IEPS 2Appendix 1) and the BKA of Control Knowledge from Information Technology Control Knowledge Requirements (IEPS 2-Appendix 2a). As seen in Table 1, IFAC specifies 38 main topic areas for these six BKAs. (In addition, as will be discussed later, IFAC further delineates the 38 main topic areas into 91 subtopics). Next, we selected eleven representative AIS texts following the examples used by Bain et al. (2002). We examined newer editions of the same AIS textbooks with the exception of the Boockholdt, Wilkinson and Cerullo, and Smith and Smith books that are no longer published and with the addition of the text by Bagranoff, Simkin and Strand. As found by Bain et al. (2002), these eleven texts fall into two categories: the traditional AIS texts and specialty AIS texts. The specialty AIS texts are newer editions of the ones examined by Bain et al. (2002): Dunn, Cherrington \& Holander, Heagy, Murthy \& Groomer and Perry \& Schneider. The traditional AIS textbook market has no dominant perfomer (Macur,1998). 
For our first level of IFAC compliance analysis we surveyed each AIS text at the chapter level to determine an estimated page count of IFAC broad knowledge area category coverage. Then for our second level of IFAC compliance we surveyed each AIS text at the learning objective level to compile the number of learning objectives that address IFAC main topics and subtopics coverage. Moreover, these two categories were analyzed on two dimensions: 1) percentage of the text devoted to each suggested IFAC topic and 2) percentage of the IFAC topics covered by the text.

\section{Discussion Of Findings}

As noted above, the first level of analysis looked at textbook coverage of IFAC's six BKAs (Table 1) as a percentage of the text, based on page count. If a page count represented less than one half of one percent coverage, it was assigned a zero percent. With approximately 440 pages as the average number of pages per text, any count less than one half of a percent equates to fewer than 2.2 pages of coverage in an entire textbook. In applying this rule, the highest percentage we found that became a zero was .0033 representing only 1.5 pages in a 440 page text. The results of this analysis are presented in Table 2. It should be noted that the last row in this Table is not a total of the percentages above it but represents the number of BKA's that have some text coverage. For example the Bodnar text addresses all the six BKAs so they get a $100 \%$ while Bagranoff addressed only four of the six BKAs for a $67 \%$ rating. The Bodnar and the Gelinas (categorized as a traditional text) texts provided coverage in all six BKAs (100\%), while other traditional texts only had coverage of $67 \%$. As would be expected, the specialty text of Perry shows $100 \%$ of its page count addressing topics found in the BKA of IT Architecture, which is only 1 out of 6 BKAs or $17 \%$. Next is the Heagy at 50\% with the remaining two coming in at $67 \%$ coverage of the BKAs.

To examine whether all topics receive equal emphasis, a Friedman's two-way ANOVA was conducted on the ranks for each of the topics across the 11 textbooks. The calculated Chi Square is 48.9 which is significantly greater than the Chi Square critical value of 16.75 and thus the null hypothesis that the topics are treated equally across texts is rejected with a p-value smaller than .005 . Table 3 presents the results of this test and the rankings. As seen here, although the BKAs are not covered equally, they are ranked fairly consistently across texts especially at both ends of the extremes of coverage. IT Architecture was ranked first in priority by all the texts while IT Management was almost uniformly ranked last with most of the texts giving it $0 \%$ coverage. IT Controls Knowledge was the next most consistently ranked close to 2 and close behind was Systems Acquisition and Development. Alternately, IT Strategy and Business Process Enablement were not well covered by most of the texts with many having $0 \%$ coverage.

Continuing this analysis of page count coverage, the Spearman correlation analysis on ranks indicates a fairly considerable correlation among the various textbooks as seen in Table 4 . The highest correlation is between two nontraditional texts: Heagy and Perry at $.87, \mathrm{p}<.01$. Other correlations include Moscove as significantly correlated with Romney .867, Bagranoff .8613 and Bodnar .84. After the nontraditional and traditional text correlations, the next most highly correlated text was Murthy which correlated with Perry .7986, Gelinas .7899 and Hall .7604. Dunn was the only text that was not significantly correlated with any other text. Both Romney and Perry were correlated with four other texts.

As seen in Table 1, the first BKA is IT Architecture, which includes eight main topics. Due to the diversity and fundamental importance of these topics, it is likely that AIS professors will view them to be of equal importance to the other five BKAs. Therefore, we repeated the statistical analysis discussed above on the components (main topics) of IT Architecture. Table 5 gives further details about the AIS texts' coverage, breaking out the 8 topics in IT Architecture plus the other 5 BKAs for a total of 13 topics/BKAs. Again, the last row is not a total of the percentages above it but rather represents the percentage of IFAC recommended topics that have some text coverage. For example, the Bodnar text had 10 of the 13 topics covered for a $77 \%$. In the traditional text category Bagranoff and Gelinas did manage some coverage at $85 \%$ (11/13). Bodnar and Hall were next with $77 \%$ followed by Moscove $62 \%$ and finally Jones and Romney both at $46 \%$. In the nontraditional category Heagy had coverage of $69 \%$, Murthy $67 \%$,Dunn at $54 \%$ and finally Perry at $23 \%$. 
Next, to determine if all 13 AIS topics of interest receive equal emphasis, a Friedman's two-way ANOVA was conducted on the ranks for each of the topics across the 11 textbooks. As seen in Table 6, the calculated Chi Square is 119.9 which is significantly greater than the Chi Square critical value of 28.3 and thus the null hypothesis that the topics are treated equally across texts is rejected with a p-value smaller than .005 . The results indicate that these 13 topics can be grouped into three groups: a high ranking, medium ranking and a low ranking group. The highest ranking group ranges from 1.9 to 3.5 rankings and includes: $1 \mathrm{~b}$-Transactions processing in business systems (1.9), 6-IT Control (3.1), 1g-Data organization and access (3.4) and 2-Systems Acquisition \& Development (3.5). The medium group ranges from 6.1 to 8.8 and includes: 1e-Software (6.1), 1a-General systems concepts (7.0), 1dNetworks, and electronic data transfer (8.0), 5-Business Process Enablement (8.5) and 4-IT Strategy (8.8). Finally, the lowest group ranged from 9.7 to 10.7 rankings and includes: 1c-Physical and hardware components of a system (9.7), 1f-Protocols, standards, enabling technologies (9.9), 1h-IT professionals (10.1), and 3-IT Management (10.7). An analysis of the data behind the rankings yields some interesting results. For example 3-IT Management has effectively zero coverage in 9 of the 11 texts, followed closely by both $1 \mathrm{~h}$-IT professionals and career paths in IT organization and 1c-Physical and hardware components of a system which have zero cover in 8 of 11 texts. The topic 1f-Protocols, standards, enabling technologies has zero coverage in 7 of 11 texts and 4-IT Strategy and 5Business Process Enablement have zero coverage in 6 and 5 of 11 texts respectively. One explanation for the relatively low coverage of these topics may be that they are expected to be covered in the student's general MIS course as a prerequisite for the AIS course.

A Spearman correlation analysis on ranks, seen in Table 7, indicates, as expected, not as much correlation among the various textbooks when examining the 13 AIS topics of interest as found when we only categorized the topics into the 6 BKAs (Table 4). The highest correlation was found between two nontraditional texts Murthy and Gelinas at .73, $\mathrm{p}<.01$ followed closely by Romney and Bodnar .69, $\mathrm{p}<01$, and Jones and Perry .68, $\mathrm{p}<.01$. In the middle group were Dunn and Bonar .63, $\mathrm{p}<05$ and Moscove and Bagranoff .61, $\mathrm{p}<.05$, with the lowest significant correlation between Murthy and Hall $.49, \mathrm{p}<.05$. Heagy was the only text that was not significantly correlated with any other text.

As noted above, we studied the 8 main topics that comprised IFAC's BKA IT Architecture. IFAC provides main topics for the remaining 5 BKAs as well. Overall, the six BKAs consist of 37 main topics which are further broken down into 91 subtopics, for a total of 128 topics. (For complete details of the subtopics, see www.ifac.org.) With so many topics vying for the AIS professor's time and attention, we continued our analysis of text book coverage into this deeper level of detail in order to assist the professor in the decision of what topics to include in the AIS course, given his or her considerable time constraints. For this level of detail, the page count analysis conducted above was impractical as fractions of pages and paragraphs would have to be counted, rendering the comparisons between texts meaningless. Instead, for this level of detail we shifted our focus from page counts to the text's stated Learning Objectives (LO). The results of this analysis can be found in Table 8. A text's coverage of IFAC topics was analyzed from two perspectives: 1) the percentage of the texts' learning objectives addressing these IFAC recommended topics and subtopics and 2) the percentage of IFAC topics and subtopics addressed by the text's learning objectives. Our analysis found that most of the texts' learning objectives appear to be addressing either an IFAC required topic or subtopic, with an average of approximately $93 \%$. These range from $100 \%$ for Bagranoffs' and Dunn to the lowest at a still respectable $82 \%$ for Murthy. In some cases, however, the high compliance rate may be misleading due to several learning objectives addressing a single topic or subtopic and thereby inflating the overall compliance calculation. A more accurate analysis is found by calculating what percentage of the 37 topics and 91 subtopics are addressed by the texts' learning objectives, as seen in the second and third rows respectively. This analysis reveals that Gelinas and Hall lead the way with approximately $84 \%$ and $81 \%$ coverage, followed by Murthy at approximately $65 \%$. From there the compliance ranges drops into the $40 \%$ s and $30 \%$ s with the lowest being the nontraditional/specialty Perry text at $10.8 \%$. When examining the percentage of compliance with the 91 IFAC subtopics that support the 37 topics, Gelinas and Hall still achieve compliance of $67 \%$ and $61.5 \%$ with the next highest being Heagy at $47 \%$ and Murthy with $42.9 \%$. After that, the other texts' compliances drop to the $20 \%$ s with Perry's being the lowest at $8.7 \%$. The last line of Table 8 gives the percentage of compliance with all 128 IFAC required topics and subtopics with Gelinas and Hall being the highest, Heagy and Murthy being a distant second and the rest dropping into the low $30 \%$ s and high $20 \%$ s while Perry is the lowest at $9.3 \%$. 
Overall, we found most of the AIS textbooks did not mention IFAC or the IFAC standards, and none used these standards as a guide or justification for their textbook content. However, our results show that most of the AIS texts do address many of the IFAC broad knowledge areas even though they do not attribute their choices of topics to IFAC guidelines. We suggest that if AIS professors have available AIS texts that follow a single authoritative standard such as IFAC's, a more unified topical coverage will be possible, regardless of the variances in instructor backgrounds, and as a result the AIS curricula will become more consistent throughout.

\section{CONCLUSIONS}

This paper, to the best of our knowledge, is the first to examine the compliance of eleven current AIS texts with IFAC educational IT knowledge requirements. The structure of the IFAC standards which consist of both top level BKAs as well as detailed subtopic specificity provides a useful benchmark for AIS topical coverage for the international accounting community. By using current texts and IFAC's 91 subtopics, our findings update and expand the 22 topic areas examined in the work of Bain et al. (2002). We are encouraged to note that two texts had some coverage of all of the six recommended BKAs with eight covering more than half. Furthermore, our correlation analysis finds that the texts agree in their rankings that put IT Architecture as most important, IT Controls as second, and Systems Acquisition and Development as third. In addition, as a specialized text, Perry provides extensive coverage of database skills required to support IFAC's mandate that accountants must do more than just "know" a topic but must also be able to "perform" IT tasks. We suggest that IT Management and IT Strategy, the two BKA topics that most of the texts failed to cover, would in fact be more appropriately covered in a general MIS course required for all business majors, including accounting majors.

Expanding the six BKAs to the next level of detail consisting of 13 general AIS topics reveals that the high ranking of IT Architecture in the BKA-level analysis was based entirely on extensive coverage of transaction processing systems and data organization/access methods, i.e., only two of the eight recommended topics. These findings are consistent with Bain et al. (2002). Three textbooks (Bodnar, Bagranoff and Gelinas) address $85 \%$ of the 13 topics with most of the others addressing over 50\%. The exceptions are Dunn (46\%) and Perry (23\%). Therefore at this level of detail, the AIS texts still do a good job of covering many of IFACs' main topic areas. Although most of the texts effectively give zero coverage to hardware, IT professionals, and protocols, we again suggest that these topics are more appropriate for a first level computer skills course or an MIS courses.

Finally, expanding our analysis to the coverage of IFAC's recommended 37 topics and 91 subtopics we note that the Gelinas and Hall texts exhibited noteworthy performance with greater than $80 \%$ coverage of topics and greater than $60 \%$ coverage of subtopics. However, at this level of analysis, most of the other texts dropped to $20 \%$ $30 \%$ coverage with the exception of Murthy and Heagy, each of which scored close to $50 \%$.

\section{LIMITATIONS}

This analysis includes limitations shared with the studies noted earlier as forerunners in this research stream. For example, the inclusion of other textbooks might have revealed different results, although the ones chosen do provide both breadth and depth of topic focus. In addition, as Bain et al. (2002) noted "Part of the difficulty of any study of topical coverage is the semantic understanding of the classifications and the somewhat arbitrary categorizations involved" (pg 148). It should also be noted that as AIS professors, we use or have used the Gelinas, Bagranoff, Moscove and the Perry texts, and therefore it is possible that our more intimate knowledge of them inadvertently resulted in higher IFAC topic coverage scores. However, on the other hand, a counter-balancing possibility might be that our prior use of the texts gave us a greater awareness of the texts' lack of coverage of IFAC topics.

Our study includes top level (learning objectives) and detail level (page count) analyzes. Therefore, another possible limitation might be that an author addressed an IFAC topic but did not include a LO for it, and therefore the text's IFAC coverage was underestimated. To address this possible limitation, we used a broad interpretation of a LO in order to give the text credit for addressing a topic or subtopic. And finally, the textbooks were only reviewed for their chapter materials, without consideration for the end-of-chapter exercises, cases, or AIS 
projects which, if counted, might increase the number of pages and percentage of text coverage of selected topics. Future studies may choose to specifically review these items to address IFAC's admonition that "professional accountants must have effective practical skills as well as theoretical knowledge" (IEPS 2, pg 25).

\section{SUGGESTIONS FOR FUTURE RESEARCH}

The challenges to those teaching the AIS course(s) are numerous. Not only does the breadth of IT topics to be covered continue to expand, but also agreement as to which topics are of most importance is a moving target. For example, over a decade ago, Gallun et al. (1993) noted that many CPAs were not worried about computer viruses. By the next decade, the majority of academics and professionals reported that information security and internal controls were of top priority (Chang and Hwang, 2003). Unlike other accounting courses such as Auditing or Intermediate Accounting, the AIS course did not begin with a core set of agreed upon topics (Bain et al., 2002). In addition, research has shown that the IT knowledge of AIS educators varies widely, and some topics may not be covered as adequately in the classroom as desired by practitioners (Greenstein and McKee, 2004). Therefore, accounting faculty teaching the AIS course often have to rely on textbooks to provide them with support information about the IT topics of importance. Although many will supplement these texts with course material on emerging topics from reliable sources on the Internet (Richtermeyer and Kovar, 2001; Wibowo, Albohali, and Solak, 2002) as well as professional publications (Schiff and Lavine, 2001), the textbook is expected to remain a valuable cornerstone of AIS courses.

In order to assist the AIS professor in choosing a textbook, this paper has reviewed the contents of eleven AIS texts through the framework of the IT knowledge components suggested by IFAC. It has found that current AIS texts are addressing many of the IFAC broad areas of knowledge, although with varying emphasis on selected topics. The analysis presented here can be used to determine when and what additional materials may be required to provide the full course coverage. Furthermore, we remind AIS educators that the IFAC panel recognized that the required IT topics are too numerous to be covered in only one AIS course, and recommended a minimum of two courses. In fact, acquiring such breadth of IT knowledge might only be reasonably obtained through a specific AIS program of study as identified by Bryant et al. (1999).

Looking ahead, we see many opportunities for additional research in AIS curricula issues. Now that IFAC have provided extensive guidance for a consensus of topical coverage, and textbooks are providing support for these topics, one area of research might be to examine how AIS instructors decide which topics to emphasize in their courses as well as teaching methods and instructional materials used to support these topics. For example, antecedents to topic selection and emphasis might be found to be institutional factors, instructor attributes, and/or value of AIS instructor efforts in terms of promotion and tenure. Finally, a review of four leading accounting education journals for the period 2000-2002 (Watson et al., 2003) revealed the paucity of research devoted to the AIS course. Their review noted one article discussing the use of process mapping (Jones and Lancaster, 2001), one article examining student perceptions toward technology (Bhattacharjee and Shaw, 2001), and one AIS instructional case (Knapp and Knapp, 2000), suggesting that there is ample room for more research in this important area.

\section{REFERENCES}

1. Bain, C., A. Blankley., and L. Smith, An examination of topical coverage for the first accounting information systems course Journal of Information Systems 16(2), 143-164, 2002.

2. Bhattacharjee, S. and L. Shaw, Evidence that independent research projects improve accounting students' technology -related perceptions and skill Accounting Education, 10(1), 83-103, 2001.

3. Bryant, S., J. Weishar, and D. Fordham, A survey of accounting information systems programs in U.S. colleges and universities The Review of Accounting Information Systems, 3(2), 1-11, 1999.

4. Carnaghan, C. Discussion of IT assurance competencies International Journal of Accounting Information Systems, 5, 267-273, 2004.

5. Cerullo, M. Content of the accounting information systems course Journal of Data Education (January), 19-21,1981. 
6. Chang, C. and N. Hwang, Accounting education, firm training, and information technology: a research note, Accounting Education 12(4), 441-450, 2003.

7. Chayeb, L. and P. Best, The accounting information systems curriculum: compliance with IFAC requirements Proceedings of the International Conference on Innovation in Accounting Teaching and Learning, Hobart, Tasmania, February 2005. Retrieved from www.utas.edu.au/accg/conference/papers/Chayeb\%20Best\%20paper.pdf on 4-16-06.

8. Davis, G. Computer curriculum for accountants and auditors-present and prospective. in Education for Expanding Computer Curriculums (New York, AICPA), 1976.

9. Davis, G. Information systems curricula in the business school. Interface, Spring, 2-4, 1979.

10. Davis, J. and R. Leitch, Accounting information systems courses and curricula: new perspectives. Journal of Information Systems 3(1) 153-166, 1988.

11. Fordham, D. New roles for AIS courses: a surprising finding from a case study. Journal of Information Systems, Spring, 19(1), 113-129, 2005.

12. Gallun, R., D. Heagy, and H. Lindsay, How CPAs Use Computers. Journal of Accountancy, Jaunary, 3841, 1993.

13. Greenstein, M. and T. McKee, Assurance practitioners' and educators' self-perceived IT knowledge level: an empirical assessment. International Journal of Accounting Information Systems, 5, 213-243, 2004.

14. Groomer, S. and U. Murthy, An empirical analysis of the accounting information systems course. Journal of Information Systems, 10 (2), 103-127, 1996.

15. Heagy, C. and P. McMickle, An empirical investigation of the accounting systems course: academic practice versus practitioner needs. Issues in Accounting Education, 3(1), 96-108, 1988.

16. Hogan, P. Accounting Information Systems-Current Curricua. Faculty of Commerce Working Paper Series, 2003, retrieved from www.csu.edu.au/faculty/commerce/research/research/2003/20-03.pdf on 10-17-06.

17. International Federation of Accountants. http://www.ifac.org.

18. International Federation of Accountants Education Committee. International Education Guideline 11: Information Technology for Professional Accountants. New York, IFAC. www.Ifac.org., 2003.

19. Hermanson, D., M. Hill, and D. Ivancevich, D. Information technology in the undergraduate accounting curriculum. The Review of Accounting Information Systems 3(4):1-9, 1999.

20. Jones, R. and K. Lancaster, Process mapping and scripting in the accounting information systems (AIS) curriculum. Accounting Education, 10(3), 263-278, 2001.

21. Knapp, M. and C. Knapp, Perry Drug Stores, Inc: accounting and control issues for inventory in a retail environment. Issues in Accounting Education, 15(2), 237-255, 2000.

22. Macur, K. The curricular content of accounting information systems. The Review of Accounting Information Systems, 2(3): 11-19, 1998.

23. Palmer, K., D. Ziegenfuss., and R. Pinsker, International knowledge, skills, and abilities of auditors/accountants. Managerial Auditing Journal, 19(7), 889-896, 2004.

24. Richtermeyer, S. and S. Kovar, AIS education: incorporating trends in technology into the curriculum. Review of Business Information Systems 5 (4), 1-7, 2001.

25. Schiff, A. and M. Lavine, A comprehensive bibliography of professional journal articles on accounting information systems. Review of Business Information Systems, 5(3), 87-100, 2001.

26. Theuri, P. and R. Gunn, Accounting information systems course structure and employer systems skills expectations. Journal of Accounting Education, 16(1), 101-121, 1998.

27. Watson, S., B. Apostolou, J. Hassell, and S. Webber, Accounting education literature review 2000-2002. Journal of Accounting Education, 21, 267-325, 2003.

28. Wessels, P., Critical information and communication technology (ICT) skills for professional accountants. Meditari Accountancy Rsearch 13(1), 87-103, 2005.

29. Wibowo, K., M. Albohali, and J. Solak, A note on the effect of faculty information resources on instructional materials and research: a correlation study. International Journal of Instructional Media, 29(4), 365-376, 2002.

30. Wu, F. Teaching Accounting Information Systems: A Synthesis Issues in Accounting Education, 1, 132146,198 
Table 1

Broad Knowledge Areas and Example Topics (www.ifac.org)

\begin{tabular}{|c|c|c|c|c|c|}
\hline 1. IT Architecture & $\begin{array}{c}\text { 2. Systems Acquisition/ } \\
\text { Development }\end{array}$ & 3. Management of IT & 4. IT Strategy & $\begin{array}{c}\text { 5. Business Process } \\
\text { Enablement }\end{array}$ & $\begin{array}{l}\text { 6. IT Control Knowledge } \\
\text { and Requirements }\end{array}$ \\
\hline General systems concepts & $\begin{array}{l}\text { System acquisition } \\
\text { /development } \\
\text { methodology }\end{array}$ & IT organization & $\begin{array}{l}\text { Enterprise strategy and } \\
\text { vision }\end{array}$ & $\begin{array}{l}\text { Stakeholders and their } \\
\text { requirements }\end{array}$ & Control frameworks \\
\hline \multirow{4}{*}{$\begin{array}{l}\text { Transaction processing in } \\
\text { typical business and } \\
\text { accounting applications }\end{array}$} & \multirow[t]{4}{*}{$\begin{array}{l}\text { Investigation and } \\
\text { feasibility study }\end{array}$} & \multirow{4}{*}{$\begin{array}{l}\text { Management of IT } \\
\text { operations, effectiveness } \\
\text { and efficiency }\end{array}$} & \multirow[t]{4}{*}{$\begin{array}{l}\text { Assessment of current and } \\
\text { future IT environment }\end{array}$} & \multirow[t]{4}{*}{$\begin{array}{l}\text { The entity's business } \\
\text { models }\end{array}$} & Control objectives \\
\hline & & & & & Layers of control, \\
\hline & & & & & Responsibility for control \\
\hline & & & & & Control environment \\
\hline $\begin{array}{l}\text { Physical and hardware } \\
\text { components of a systems }\end{array}$ & $\begin{array}{l}\text { Requirements analysis and } \\
\text { initial design }\end{array}$ & Asset management & IT strategic planning & Risks and opportunities & $\begin{array}{l}\text { Control over system } \\
\text { acquisition/development }\end{array}$ \\
\hline \multirow[t]{2}{*}{$\begin{array}{l}\text { Networks and electronic } \\
\text { data transfer }\end{array}$} & \multirow[t]{2}{*}{$\begin{array}{l}\text { System design, selection } \\
\text { acquisition/development }\end{array}$} & \multirow[t]{2}{*}{$\begin{array}{l}\text { Change control and } \\
\text { problem management }\end{array}$} & \multirow{2}{*}{$\begin{array}{l}\text { Ongoing governance and } \\
\text { outcome monitoring } \\
\text { process }\end{array}$} & \multirow{2}{*}{$\begin{array}{l}\text { Impact of IT on the } \\
\text { entity's business models, } \\
\text { processes and solutions }\end{array}$} & Risk assessment \\
\hline & & & & & Control activities \\
\hline Software & System implementation & $\begin{array}{l}\text { Performance monitoring } \\
\text { and financial control over } \\
\text { IT resources }\end{array}$ & & & $\begin{array}{l}\text { Information and } \\
\text { communication }\end{array}$ \\
\hline $\begin{array}{l}\text { Protocols, standards, } \\
\text { enabling technologies }\end{array}$ & $\begin{array}{l}\text { System maintenance and } \\
\text { program changes }\end{array}$ & & & & $\begin{array}{l}\text { Monitoring of control } \\
\text { compliance }\end{array}$ \\
\hline $\begin{array}{l}\text { Data organization an } \\
\text { daccess methods }\end{array}$ & $\begin{array}{l}\text { Project } \\
\text { management/planning/con } \\
\text { trol methods and standards }\end{array}$ & & & & \\
\hline $\begin{array}{l}\text { IT professionals and } \\
\text { career paths in IT } \\
\text { organizations }\end{array}$ & & & & & \\
\hline
\end{tabular}


Table 2

Current AIS Textbooks: Percent of Pages Devoted to Each of IFACs' Six Broad Knowledge Areas (BKA)

\begin{tabular}{|c|c|c|c|c|c|c|c|c|c|c|c|}
\hline $\begin{array}{c}\text { Broad Knowledge } \\
\text { Area }\end{array}$ & $\begin{array}{c}\text { Bodnar } \\
\mathbf{2 0 0 4} \\
\% \\
46\end{array}$ & $\begin{array}{c}\text { Bagranoff } \\
\mathbf{2 0 0 5} \\
\% \\
46\end{array}$ & $\begin{array}{c}\text { Moscove } \\
\mathbf{2 0 0 3} \\
\% \\
38\end{array}$ & $\begin{array}{c}\text { Jones } \\
2006 \\
\% \\
62\end{array}$ & $\begin{array}{c}\text { Romney } \\
\mathbf{2 0 0 6} \\
\% \\
43\end{array}$ & $\begin{array}{c}\text { Gelinas } \\
\mathbf{2 0 0 4} \\
\% \\
64\end{array}$ & $\begin{array}{l}\text { Hall } \\
\mathbf{2 0 0 7} \\
\% \\
66\end{array}$ & $\begin{array}{c}\text { Heagy } \\
2005 \\
\% \\
79\end{array}$ & $\begin{array}{c}\text { Dunn } \\
2005 \\
\% \\
54\end{array}$ & $\begin{array}{c}\text { Murthey } \\
2006 \\
\% \\
63\end{array}$ & 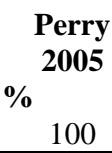 \\
\hline $\begin{array}{l}\text { 2. Systems } \\
\text { Acquistion And } \\
\text { Development }\end{array}$ & 22 & 22 & 24 & 15 & 20 & 12 & 13 & 17 & 32 & 8 & 0 \\
\hline 3. IT Management & 1 & 0 & 0 & 0 & 0 & 1 & 0 & 0 & 0 & 0 & 0 \\
\hline 4. IT Strategy & 2 & 0 & 0 & 0 & $0^{\mathrm{a}}$ & 4 & 2 & 0 & 16 & 6 & 0 \\
\hline $\begin{array}{l}\text { 5. Business } \\
\text { Process } \\
\text { Enablement } \\
\end{array}$ & 1 & 1 & 3 & 8 & 6 & 6 & 0 & 0 & 0 & 0 & 0 \\
\hline $\begin{array}{l}\text { 6. IT Controls } \\
\text { Knowledge } \\
\text { Requirements } \\
\end{array}$ & 32 & 29 & 34 & 15 & 30 & 18 & 26 & 15 & 9 & 8 & 0 \\
\hline $\begin{array}{l}\text { Percentage } \\
\text { coverage of IFAC } \\
\text { Broad Knowledge } \\
\text { Areas }\end{array}$ & 100 & 67 & 67 & 67 & 67 & 100 & 67 & 50 & 67 & 67 & 17 \\
\hline
\end{tabular}

Note this value was .0023 and rounded to zero. 
Table 3

Results of Friedmans Two Way Nonparametric Analysis of Variance on Ranks of the IFAC's Six Broad Knowledge Areas (BKA) across the 11 text books.

\begin{tabular}{|c|c|c|c|c|c|c|c|c|c|c|c|c|}
\hline \multirow{2}{*}{$\begin{array}{c}\text { Friedman's Two-Way } \\
\text { ANOVA: } \\
\mathrm{X}^{2}=\mathbf{4 8 . 9 ,} \mathrm{P}<.005 \\
\text { Bodnar } 2004 \\
\end{array}$} & \multicolumn{2}{|c|}{ 1. IT Architecture } & \multicolumn{2}{|c|}{$\begin{array}{c}\text { 2. Systems } \\
\text { Acquistion And } \\
\text { Development }\end{array}$} & \multicolumn{2}{|c|}{ 3.IT Management } & \multicolumn{2}{|c|}{$\begin{array}{l}\text { 4.Information } \\
\text { Technology } \\
\text { Strategy }\end{array}$} & \multicolumn{2}{|c|}{$\begin{array}{l}\text { 5. Business Process } \\
\text { Enablement }\end{array}$} & \multicolumn{2}{|c|}{$\begin{array}{l}\text { 6. IT Controls } \\
\text { Knowledge } \\
\text { Requirements }\end{array}$} \\
\hline & $46 \%$ & 1.0 & $22 \%$ & 3.0 & $1 \%$ & 5.5 & $2 \%$ & 4.0 & $1 \%$ & 5.5 & $32 \%$ & 2.0 \\
\hline Bagranoff 2005 & $46 \%$ & 1.0 & $22 \%$ & 3.0 & $0 \%$ & 5.5 & $0 \%$ & 5.5 & $1 \%$ & 4.0 & $29 \%$ & 2.0 \\
\hline Moscove 2003 & $38 \%$ & 1.0 & $24 \%$ & 3.0 & $0 \%$ & 5.5 & $0 \%$ & 5.5 & $3 \%$ & 4.0 & $34 \%$ & 2.0 \\
\hline Jones \& Rama 8th 2006 & $62 \%$ & 1.0 & $15 \%$ & 2.5 & $0 \%$ & 5.5 & $0 \%$ & 5.5 & $8 \%$ & 4.0 & $15 \%$ & 2.5 \\
\hline $\begin{array}{l}\text { Romney \& Steinbart } \\
\text { 10th } 2006\end{array}$ & $43 \%$ & 1.0 & $20 \%$ & 3.0 & $0 \%$ & 5.5 & $0 \%$ & 5.5 & $6 \%$ & 4.0 & $30 \%$ & 2.0 \\
\hline Gelinas 2004 & $64 \%$ & 1.0 & $12 \%$ & 3.0 & $1 \%$ & 6.0 & $4 \%$ & 5.0 & $6 \%$ & 4.0 & $18 \%$ & 2.0 \\
\hline Hall 2007 & $66 \%$ & 1.0 & $13 \%$ & 3.0 & $0 \%$ & 5.5 & $2 \%$ & 4.0 & $0 \%$ & 5.5 & $26 \%$ & 2.0 \\
\hline Heagy 2005 & $79 \%$ & 1.0 & $17 \%$ & 2.0 & $0 \%$ & 5.5 & $0 \%$ & 5.5 & $0 \%$ & 5.5 & $15 \%$ & 3.0 \\
\hline Dunn,2005 & $54 \%$ & 1.0 & $32 \%$ & 2.0 & $0 \%$ & 5.5 & $16 \%$ & 3.0 & $0 \%$ & 5.5 & $9 \%$ & 4.0 \\
\hline Murthey 2006 & $63 \%$ & 1.0 & $8 \%$ & 2.5 & $0 \%$ & 5.5 & $6 \%$ & 4.0 & $0 \%$ & 5.5 & $8 \%$ & 2.5 \\
\hline Perry 2005 & $100 \%$ & 1.0 & $0 \%$ & 4.0 & $0 \%$ & 4.0 & $0 \%$ & 4.0 & $0 \%$ & 4.0 & $0 \%$ & 4.0 \\
\hline Average Rankings & & 1.0 & & 2.8 & & 5.4 & & 4.7 & & 4.7 & & 2.5 \\
\hline
\end{tabular}




\section{Table 4}

Spearman Correlation Coefficients on Ranks of Six IFAC Broad Knowledge Areas within Textbooks ${ }^{\mathrm{a}}$

\begin{tabular}{|c|c|c|c|c|c|c|c|c|c|c|c|}
\hline & $\begin{array}{c}\text { Bodnar } \\
2004 \\
\end{array}$ & $\begin{array}{c}\text { Bagranoff } \\
2005 \\
\end{array}$ & $\begin{array}{c}\text { Perry } \\
2005 \\
\end{array}$ & $\begin{array}{c}\text { Moscove } \\
2003 \\
\end{array}$ & $\begin{array}{c}\text { Jones } \\
2006 \\
\end{array}$ & $\begin{array}{c}\text { Romney } \\
2006\end{array}$ & $\begin{array}{c}\text { Gelinas } \\
2004 \\
\end{array}$ & $\begin{array}{l}\text { Hall } \\
2007 \\
\end{array}$ & $\begin{array}{c}\text { Heagy } \\
2005\end{array}$ & $\begin{array}{c}\text { Dunn } \\
2005 \\
\end{array}$ & $\begin{array}{c}\text { Murthey } \\
2006 \\
\end{array}$ \\
\hline Bodnar 2004 & 1 & & & & & & & & & & \\
\hline Bagranoff 2005 & $\begin{array}{c}\mathbf{0 . 8 3 3 9} \\
0.01\end{array}$ & 1 & & & & & & & & & \\
\hline Perry 2005 & -0.3904 & -0.3002 & 1 & & & & & & & & \\
\hline Moscove 2003 & $\begin{array}{c}0.8437 \\
0.01\end{array}$ & $\begin{array}{c}0.8613 \\
0.01\end{array}$ & $\begin{array}{c}-0.6618 \\
.05\end{array}$ & 1 & & & & & & & \\
\hline Jones 2006 & -0.0903 & 0.2228 & 0.4137 & 0.1085 & 1 & & & & & & \\
\hline Romney 2006 & $\begin{array}{c}0.6268 \\
.05\end{array}$ & $\begin{array}{c}0.7297 \\
.01\end{array}$ & -0.3854 & $\begin{array}{c}0.8670 \\
0.01\end{array}$ & $\begin{array}{c}0.5582 \\
.05\end{array}$ & 1 & & & & & \\
\hline Gelinas 2004 & -0.1407 & -0.1278 & 0.7141 & -0.2263 & $\begin{array}{c}0.7810 \\
.01\end{array}$ & 0.2295 & 1 & & & & \\
\hline Hall 5th 2007 & 0.0655 & -0.1154 & $\begin{array}{c}0.7945 \\
.01\end{array}$ & -0.3632 & 0.1254 & -0.2338 & $\begin{array}{c}0.6243 \\
.05\end{array}$ & 1 & & & \\
\hline Heagy 2005 & -0.1374 & 0 & $\begin{array}{c}0.8701 \\
0.01\end{array}$ & -0.4766 & 0.1601 & -0.4120 & 0.3754 & $\begin{array}{c}0.7661 \\
.01\end{array}$ & 1 & & \\
\hline Dunn 2005 & 0.4013 & 0.3450 & 0.0657 & 0.1356 & -0.0319 & 0 & -0.0479 & 0.0121 & 0.1660 & 1 & \\
\hline Murthey 2006 & -0.0358 & -0.1765 & $\begin{array}{c}0.7986 \\
.01 \\
\end{array}$ & -0.3991 & 0.3963 & -0.1431 & $\begin{array}{c}0.7899 \\
.01 \\
\end{array}$ & $\begin{array}{c}0.7604 \\
.01 \\
\end{array}$ & $\begin{array}{c}0.5816 \\
.05 \\
\end{array}$ & 0.4325 & 1 \\
\hline
\end{tabular}

${ }^{a}$ Numbers in bold indicate significance from zero and the bottom number indicates the p-value. 
Table 5

Current AIS Textbooks: Percent of Pages Devoted to Each of 13 IFAC topics/BKAs of AIS Interest

\begin{tabular}{|c|c|c|c|c|c|c|c|c|c|c|c|}
\hline & $\begin{array}{c}\text { Bodnar } \\
2004\end{array}$ & $\begin{array}{l}\text { Bagranof } \\
\text { f } 2005\end{array}$ & $\begin{array}{l}\text { Moscove } \\
2003\end{array}$ & $\begin{array}{l}\text { Jones } \\
2006\end{array}$ & $\begin{array}{l}\text { Romney } \\
2006\end{array}$ & $\begin{array}{c}\text { Gelinas } \\
2004\end{array}$ & $\begin{array}{l}\text { Hall } \\
2007\end{array}$ & $\begin{array}{l}\text { Heagy } \\
2005\end{array}$ & $\begin{array}{l}\text { Dunn } \\
2005\end{array}$ & $\begin{array}{l}\text { Murthey } \\
2006\end{array}$ & $\begin{array}{l}\text { Perry } \\
2005\end{array}$ \\
\hline & $\%$ & $\%$ & $\%$ & $\%$ & $\%$ & $\%$ & $\%$ & $\%$ & $\%$ & $\%$ & $\%$ \\
\hline \multicolumn{12}{|l|}{ Broad Knowledge Area } \\
\hline $\begin{array}{l}\text { 1a. General systems } \\
\text { concepts }\end{array}$ & 2 & 1 & 0 & 1 & 1 & 4 & 6 & 19 & 0 & 16 & 0 \\
\hline $\begin{array}{l}\text { 1b. Transaction processing } \\
\text { in business systems }\end{array}$ & 30 & 11 & 15 & 30 & 32 & 29 & 38 & 36 & 43 & 14 & 9 \\
\hline $\begin{array}{l}\text { 1c. Physical and hardware } \\
\text { components of a system }\end{array}$ & 0 & 6 & 0 & 0 & 0 & 6 & 0 & 0 & 0 & 3 & 0 \\
\hline $\begin{array}{l}\text { 1d. Networks, and electronic } \\
\text { data transfer }\end{array}$ & 2 & 6 & 1 & 0 & 0 & 3 & 6 & 2 & 0 & 8 & 0 \\
\hline 1e. Software & 1 & 9 & 7 & 9 & 1 & 4 & 4 & 6 & 5 & 4 & 73 \\
\hline $\begin{array}{l}\text { 1f. Protocols, standards, } \\
\text { enabling technologies }\end{array}$ & $0^{\mathrm{a}}$ & 1 & 2 & 0 & 0 & $0^{\mathrm{b}}$ & 2 & 2 & 0 & 0 & 0 \\
\hline $\begin{array}{l}\text { 1g. Data organization and } \\
\text { access methods }\end{array}$ & 10 & 10 & 12 & 22 & 9 & 18 & 12 & 14 & 6 & 18 & 19 \\
\hline $\begin{array}{l}\text { 1h. IT professionals and } \\
\text { career paths in IT } \\
\text { organization }\end{array}$ & 1 & 2 & 1 & 0 & 0 & 0 & 0 & $0^{\mathrm{b}}$ & 0 & 0 & 0 \\
\hline $\begin{array}{l}\text { 2. Systems Acquisition And } \\
\text { Development }\end{array}$ & 22 & 22 & 24 & 15 & 20 & 12 & 13 & 17 & 32 & 8 & 0 \\
\hline 3. IT Management & 1 & 0 & 0 & 0 & 0 & 1 & 0 & 0 & 0 & 0 & 0 \\
\hline $\begin{array}{l}\text { 4. Information Technology } \\
\text { Strategy }\end{array}$ & 2 & 0 & 0 & 0 & 0 & 4 & 2 & 0 & 16 & 6 & 0 \\
\hline $\begin{array}{l}\text { 5. Business Process } \\
\text { Enablement }\end{array}$ & 1 & 1 & 3 & 8 & 6 & 6 & 0 & 0 & 0 & 0 & 0 \\
\hline $\begin{array}{l}\text { 6. IT Controls Knowledge } \\
\text { Requirements }\end{array}$ & 32 & 29 & 34 & 15 & 30 & 18 & 26 & 15 & 9 & 8 & 0 \\
\hline $\begin{array}{l}\text { Percentage coverage of } \\
\text { IFAC Broad Knowledge } \\
\text { Areas }\end{array}$ & 85 & 85 & 69 & 54 & 54 & 85 & 69 & 62 & 46 & 69 & 23 \\
\hline
\end{tabular}

${ }^{a}$ Note this value was .0033 and rounded to zero

${ }^{\mathrm{b}}$ Note this value was .0023 and rounded to zero. 
Table 6

Results of Friedmans Two Way Analysis of Variance of the Thirteen AIS Topics of interest across the Eleven text books.

Table Chi Square is 28.3 at $p=.005$ level with 12 degrees of freedom. The calculated Chi Square is 119.9 thus the null hypothesis that the Thirteen AIS Topics of interest are covered equally across text books is rejected.

\begin{tabular}{|c|c|c|c|c|c|c|c|c|c|c|c|c|c|c|c|c|c|c|c|c|c|c|c|c|c|c|}
\hline \multirow{2}{*}{ 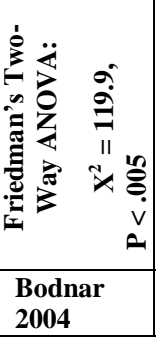 } & \multicolumn{2}{|c|}{ 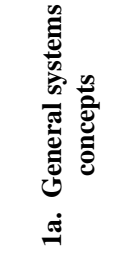 } & \multicolumn{2}{|c|}{ 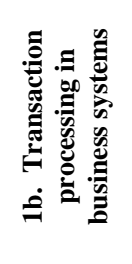 } & \multicolumn{2}{|c|}{ 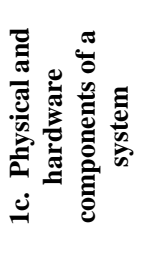 } & \multicolumn{2}{|c|}{ 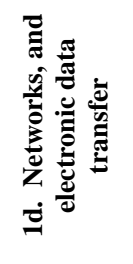 } & \multicolumn{2}{|c|}{ 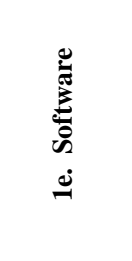 } & \multicolumn{2}{|c|}{ 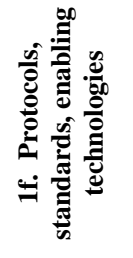 } & \multicolumn{2}{|c|}{ 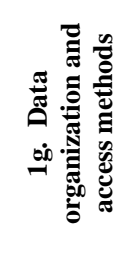 } & \multicolumn{2}{|c|}{ 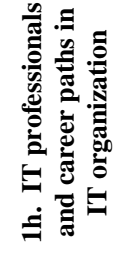 } & \multicolumn{2}{|c|}{ 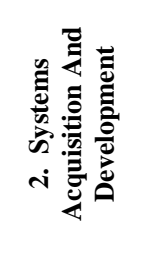 } & \multicolumn{2}{|c|}{ 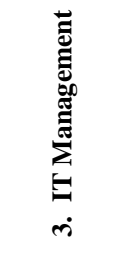 } & \multicolumn{2}{|c|}{ 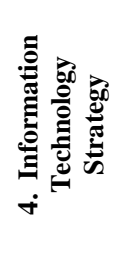 } & \multicolumn{2}{|c|}{ 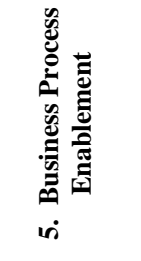 } & \multicolumn{2}{|c|}{ 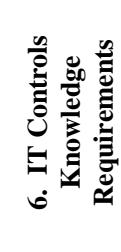 } \\
\hline & $2 \%$ & 6.0 & $30 \%$ & 2.0 & $0 \%$ & 12.5 & $2 \%$ & 6.0 & $1 \%$ & 9.5 & $0 \%$ & 12.5 & $10 \%$ & 4.0 & $1 \%$ & 9.5 & $22 \%$ & 3.0 & $1 \%$ & 9.5 & $2 \%$ & 6.0 & $1 \%$ & 9.5 & $32 \%$ & 1.0 \\
\hline $\begin{array}{l}\text { Bagranof } \\
\text { f } 2005\end{array}$ & $1 \%$ & $\begin{array}{c}10 . \\
0\end{array}$ & $11 \%$ & 3.5 & $6 \%$ & 6.5 & $6 \%$ & 6.5 & $9 \%$ & 5.0 & $1 \%$ & 10.0 & $11 \%$ & 3.5 & $2 \%$ & 8.0 & $22 \%$ & 2.0 & $0 \%$ & 12.5 & $0 \%$ & 12.5 & $1 \%$ & 10.0 & $29 \%$ & 1.0 \\
\hline $\begin{array}{l}\text { Perry } \\
2005 \\
\end{array}$ & $0 \%$ & 8.5 & $9 \%$ & 3.0 & $0 \%$ & 8.5 & $0 \%$ & 8.5 & $\begin{array}{r}73 \\
\% \\
\end{array}$ & 1.0 & $0 \%$ & 8.5 & $19 \%$ & 2.0 & $0 \%$ & 8.5 & $0 \%$ & 8.5 & $0 \%$ & 8.5 & $0 \%$ & 8.5 & $0 \%$ & 8.5 & $0 \%$ & 8.5 \\
\hline $\begin{array}{l}\text { Moscove } \\
2003 \\
\end{array}$ & $0 \%$ & $\begin{array}{c}11 . \\
5\end{array}$ & $15 \%$ & 3.0 & $0 \%$ & 11.5 & $1 \%$ & 8.5 & $7 \%$ & 5.0 & $2 \%$ & 7.0 & $12 \%$ & 4.0 & $1 \%$ & 8.5 & $24 \%$ & 2.0 & $0 \%$ & 11.5 & $0 \%$ & 11.5 & $3 \%$ & 6.0 & $34 \%$ & 1.0 \\
\hline $\begin{array}{l}\text { Jones } \\
2006\end{array}$ & $1 \%$ & 7.0 & $30 \%$ & 1.0 & $0 \%$ & 10.5 & $0 \%$ & 10.5 & $9 \%$ & 5.0 & $0 \%$ & 10.5 & $22 \%$ & 2.0 & $0 \%$ & 10.5 & $15 \%$ & 3.5 & $0 \%$ & 10.5 & $0 \%$ & 10.5 & $8 \%$ & 6.0 & $15 \%$ & 3.5 \\
\hline $\begin{array}{l}\text { Romney } \\
2006 \\
\end{array}$ & $1 \%$ & 6.5 & $32 \%$ & 1.0 & $0 \%$ & 10.5 & $0 \%$ & 10.5 & $1 \%$ & 6.5 & $0 \%$ & 10.5 & $9 \%$ & 4.0 & $0 \%$ & 10.5 & $20 \%$ & 3.0 & $0 \%$ & 10.5 & $0 \%$ & 10.5 & $6 \%$ & 5.0 & $30 \%$ & 2.0 \\
\hline $\begin{array}{l}\text { Gelinas } \\
2004 \\
\end{array}$ & $4 \%$ & 8.0 & $29 \%$ & 1.0 & $6 \%$ & 5.5 & $3 \%$ & 10.0 & $4 \%$ & 8.0 & $0 \%$ & 12.5 & $18 \%$ & 2.5 & $0 \%$ & 12.5 & $12 \%$ & 4.0 & $1 \%$ & 11.0 & $4 \%$ & 8.0 & $6 \%$ & 5.5 & $18 \%$ & 2.5 \\
\hline $\begin{array}{l}\text { Hall } \\
2007\end{array}$ & $6 \%$ & 5.5 & $38 \%$ & 1.0 & $0 \%$ & 11.5 & $6 \%$ & 5.5 & $4 \%$ & 7.0 & $2 \%$ & 8.5 & $12 \%$ & 4.0 & $0 \%$ & 11.5 & $13 \%$ & 3.0 & $0 \%$ & 11.5 & $2 \%$ & 8.5 & $0 \%$ & 11.5 & $26 \%$ & 2.0 \\
\hline $\begin{array}{l}\text { Heagy } \\
2005 \\
\end{array}$ & $19 \%$ & 2.0 & $36 \%$ & 1.0 & $0 \%$ & 11.0 & $2 \%$ & 7.5 & $6 \%$ & 6.0 & $2 \%$ & 7.5 & $14 \%$ & 5.0 & $0 \%$ & 11.0 & $17 \%$ & 3.0 & $0 \%$ & 11.0 & $0 \%$ & 11.0 & $0 \%$ & 11.0 & $15 \%$ & 4.0 \\
\hline $\begin{array}{l}\text { Dunn } \\
2005 \\
\end{array}$ & $0 \%$ & 9.5 & $43 \%$ & 1.0 & $0 \%$ & 9.5 & $0 \%$ & 9.5 & $5 \%$ & 6.0 & $0 \%$ & 9.5 & $6 \%$ & 5.0 & $0 \%$ & 9.5 & $32 \%$ & 2.0 & $0 \%$ & 9.5 & $16 \%$ & 3.0 & $0 \%$ & 9.5 & $9 \%$ & 4.0 \\
\hline $\begin{array}{l}\text { Murthey } \\
2006\end{array}$ & $16 \%$ & 2.0 & $14 \%$ & 3.0 & $3 \%$ & 9.0 & $8 \%$ & 5.0 & $4 \%$ & 8.0 & $0 \%$ & 11.5 & $18 \%$ & 1.0 & $0 \%$ & 11.5 & $8 \%$ & 5.0 & $0 \%$ & 11.5 & $6 \%$ & 7.0 & $0 \%$ & 11.5 & $8 \%$ & 5.0 \\
\hline $\begin{array}{l}\text { Average } \\
\text { Rankings }\end{array}$ & & 7.0 & & 1.9 & & 9.7 & & 8.0 & & 6.1 & & 9.9 & & 3.4 & & 10.1 & & 3.5 & & 10.7 & & 8.8 & & 8.5 & & 3.1 \\
\hline
\end{tabular}


Table 7

Spearman Correlation Coefficients on Ranks of Thirteen AIS Topics of Interest within Textbooks

\begin{tabular}{|c|c|c|c|c|c|c|c|c|c|c|c|}
\hline & $\begin{array}{c}\text { Bodnar } \\
2004\end{array}$ & $\begin{array}{c}\text { Bagranof } \\
\text { f } 2005\end{array}$ & $\begin{array}{c}\text { Perry } \\
2005\end{array}$ & $\begin{array}{c}\text { Moscove } \\
2003\end{array}$ & $\begin{array}{c}\text { Jones } \\
2006\end{array}$ & $\begin{array}{c}\text { Romney } \\
2006\end{array}$ & $\begin{array}{c}\text { Gelinas } \\
2004\end{array}$ & $\begin{array}{c}\text { Hall 5th } \\
2007\end{array}$ & $\begin{array}{c}\text { Heagy } \\
2005\end{array}$ & $\begin{array}{l}\text { Dunn } \\
2005\end{array}$ & $\begin{array}{c}\text { Murthey } \\
2006\end{array}$ \\
\hline Bodnar 2004 & 1 & & & & & & & & & & \\
\hline \multirow{2}{*}{ Bagranoff 2005} & 0.33546 & 1 & & & & & & & & & \\
\hline & & & & & & & & & & & \\
\hline \multirow[t]{2}{*}{ Perry 2005} & -0.25184 & 0.388296 & 1 & & & & & & & & \\
\hline & & & & & & & & & & & \\
\hline \multirow[t]{2}{*}{ Moscove 2003} & 0.31806 & 0.613414 & 0.397387 & 1 & & & & & & & \\
\hline & & $\mathbf{0 . 0 5}$ & & & & & & & & & \\
\hline \multirow[t]{2}{*}{ Jones 2006} & -0.41378 & -0.06055 & 0.684483 & 0.256756 & 1 & & & & & & \\
\hline & & & 0.01 & & & & & & & & \\
\hline \multirow[t]{2}{*}{ Romney 2006} & 0.6969 & 0.117512 & -0.26677 & 0.344463 & 0.050731 & 1 & & & & & \\
\hline & 0.01 & & & & & & & & & & \\
\hline Gelinas 2004 & 0.18128 & 0.173528 & 0.473292 & -0.00234 & 0.399369 & 0.314577 & 1 & & & & \\
\hline Hall 2007 & 0.43065 & -0.07212 & -0.06442 & -0.16702 & -0.34191 & 0.233045 & 0.278036 & 1 & & & \\
\hline Heagy 2005 & 0.29767 & -0.05049 & 0.04245 & -0.02792 & -0.12291 & 0.163154 & 0.071134 & 0.747646 & 1 & & \\
\hline \multirow[t]{2}{*}{ Dunn 2005} & 0.62606 & 0.095009 & -0.2606 & 0.347156 & -0.27376 & 0.538555 & -0.24835 & 0.106178 & -0.02618 & 1 & \\
\hline & 0.05 & & & & & 0.05 & & & & & \\
\hline \multirow[t]{2}{*}{ Murthey 2006} & 0.18453 & 0.218785 & 0.398813 & -0.2333 & -0.07448 & -0.15272 & 0.731343 & 0.492463 & 0.267311 & -0.38159 & 1 \\
\hline & & & & & & & 0.01 & 0.05 & & & \\
\hline
\end{tabular}

Numbers in bold indicate significance from zero and the bottom number indicates the p-value and significance. 